\title{
Supporting Physicians Who Work in Challenging Contexts: A Role for the Academic Health Center
}

\author{
Christopher P. Morley, PhD
}

Physicians who work in challenging contexts such as remote rural locations or with special populations may need support in persevering in their positions and also may suffer vicarious trauma through their work. Academic health centers may be in a position to provide much needed support to these physicians through focused continuing medical education, faculty development, practice-based research networks, and other means. (J Am Board Fam Med 2012;25:756-758.)

Caring for patients may exact a toll on the caregiver and certainly requires a level of resilience. Physicians and other healthcare providers come face to face with suffering on a daily basis that might be singularly life-changing and traumatic events for another sort of witness. The toll expresses itself in a number of ways and under a variety of different names, such as vicarious or secondary trauma, ${ }^{1-3}$ occupational stress, ${ }^{4}$ burnout,${ }^{5}$ or compassion fatigue. ${ }^{1,6}$ Although all healthcare providers may experience these phenomena as occupational hazards, those who serve in identifiably more difficult contexts have the difficulty compounded by geographic (rural) or organizational isolation, relatively low compensation, poor or unsafe working conditions, or more draining patient interactions. ${ }^{2,7}$

Fortunately, physicians tend to be resilient individuals. As $\operatorname{Reed}^{8}$ and colleagues demonstrate, primary care and specialist physicians, in both rural and nonrural settings, demonstrate similar levels of grit, ${ }^{8-10}$ defined as "perseverance and passion for long-term goals, working strenuously toward challenges, and maintaining effort

From the Department of Family Medicine, Department of Public Health \& Preventive Medicine and Department of Psychiatry \& Behavioral Sciences, SUNY Upstate Medical University, Syracuse, NY.

Funding: This article was written with funding by Health Resources and Services Administration grant D54HP23297. Conflict of interest: none declared.

Corresponding author: Christopher P. Morley, PhD, SUNY Upstate Medical University, Department of Family Medicine, College of Medicine, 750 East Adams Street, Syracuse, NY 13210 (E-mail: morleycp@upstate.edu).

See Related Article on Page 840. and interest over years despite failure, adversity, and plateaus in progress." However, primary care physicians (PCPs) appear to differ from specialists in the grit subscales related to perseverance of effort and overall ambition, and this difference is more pronounced when comparing rural primary care physicians with either their rural specialist colleagues or either primary or specialty care physicians in nonrural areas. ${ }^{10}$ It may be that individuals with higher intrinsic levels of perseverance and ambition may partially self-select into the longer training period and eventual higher compensation that goes with specialization; yet, it is also probably true that some aspects of grit, particularly perseverance, may be required for the challenges of rural practice.

Woolhouse and colleagues ${ }^{2}$ examined vicarious trauma in a different subpopulation of PCPs: Canadian PCPs who treat female drug users as a large portion of their patient panel. Although these PCPs report suffering from vicarious trauma through the hopelessness, self-defeating behaviors, and social injustices they witness through practice, they also report developing "vicarious resilience" over the course of time. In Woolhouse's sample, this appears to be a self-taught, self-preservative learned behavior.

What might we take from the various studies cited, including the most recent reports by Reed and Woolhouse? Clearly, PCPs operating in especially challenging circumstances would benefit from external support. In such especially challenging circumstances, however, the resources to provide such support are generally scarce, whether due to geography (eg, rurality), patient type (eg, drug users), or organizational structure (eg, a community health center). 
There exist both demonstrated mechanisms for providing such support and a potential means for delivery. Although the efficacy and long-term effects of Balint groups have been questioned, no doubt many PCPs have come in contact with this mechanism of support in residency and may be useful in providing support over the course of a career. ${ }^{11}$ Aside from the explicit goals of Balint groups, the facilitation of such groups may create implicit secondary benefits for PCPs treating special populations in that it may create networks that overcome the isolation experienced by these individuals. Furthermore, enabling challenging clinical assignments to be part-time endeavors may allow for a titration of trauma, burnout, and compassionfatigue inducing insults without increasing social or professional isolation, as demonstrated in a sample of Dutch healthcare providers. ${ }^{12}$ Resiliency may also be taught and maintained through workshops, as demonstrated through a curriculum developed and implemented by Longnecker and colleagues. ${ }^{13}$ Engagement in practice-based research networks (PBRNs) may also be a promising means by which to retain physicians in challenging assignments. ${ }^{14}$

The academic health center (AHC) may be a reasonable delivery mechanism for such measures, particularly in the case of PCPs. Although AHCs face concerns over relevancy to communities and community physicians, they nevertheless have recognized social duties to and potentially useful roles within the communities they serve. ${ }^{15-19}$ As a component of most AHCs, academic primary care departments often maintain large networks of volunteer or nominally compensated volunteer faculty who serve as preceptors. Many already do provide continuing medical education and faculty development activities to these community faculty members. Focusing a portion of such efforts on the support of PCPs working in challenging contexts throughout a region may take the form of professional Balint groups, ${ }^{11}$ resilience training, ${ }^{13,20}$ PBRN membership, or other networking activities. The explosion of social networking technologies over the past decade may provide additional and efficient solutions in the years to come.

Ensuring that PCPs in challenging practice contexts are first engaged as community faculty, and second providing for support through already-existent routes such as continuing medical education, faculty development, and PBRN activity would provide multiple benefits. Students receive training in underserved areas and in care for special populations, and the volunteer community faculty providing such training would benefit from support-focused continuing medical education, faculty development, and student engagement. PBRN membership focused on PCPs working in underserved/special population areas may provide career development, networking, intellectual engagement, ${ }^{14}$ and support for these physicians, and provide the basis for muchneeded research in disadvantaged populations.

Of course, in many cases, the activities described are already occurring in many academic primary care departments. However, these may happen less with forethought design and more with a focus on pragmatic needs such as teaching processes, research reports, or clinical updates, and not on physician support. What does not presently exist is a comprehensive roadmap for outreach from academic medical centers to physicians serving in challenging practice contexts with multiple, simultaneous explicit goals of medical education, physician support, and research into both the disadvantaged populations served as well as the healthcare providers who serve them. One overarching and existing mechanism to support such a goal may be through "Title VII" grants awarded in the United States by the Health Resources and Services Administration and particularly through the faculty development mechanism. ${ }^{21,22}$

As a final note, the effects of work in challenging contexts on PCPs is examined, classified, measured, and reported under a variety of related names, and research on these effects is usually context-specific (eg, comparing rural vs nonrural). As Woolhouse et $\mathrm{al}^{2}$ notes, the phenomena are understudied and worthy of continued research. In the meantime, the AHC may be positioned to serve as a beneficial moderator of these effects through already existent mechanisms and relationships.

\section{References}

1. Meadors P, Lamson A, Swanson M, White M, Sira N. Secondary traumatization in pediatric healthcare providers: compassion fatigue, burnout, and secondary traumatic stress. Omega (Westport). 2009;60: 103-28.

2. Woolhouse S, Brown JB, Thind A. "Building through the grief": vicarious trauma in a group of inner-city family physicians. J Am Board Fam Med 2012;25: $840-6$.

3. Tabor PD. Vicarious traumatization: concept analysis. J Forensic Nurs 2011;7:203-8. 
4. Iliceto P, Pompili M, Spencer-Thomas S, Ferracuti S, Erbuto D, Lester D, et al. Occupational stress and psychopathology in health professionals: an explorative study with the Multiple Indicators Multiple Causes (MIMIC) model approach. Stress 2012 June 6 [Epub ahead of print].

5. Nielsen HG, Tulinius C. Preventing burnout among general practitioners: is there a possible route? Educ Prim Care 2009;20:353-9.

6. Wee D, Myers D. Compassion satisfaction, compassion fatigue, and critical incident stress management. Int J Emerg Ment Health 2003;5:33-7.

7. Stevenson AD, Phillips CB, Anderson KJ. Resilience among doctors who work in challenging areas: a qualitative study. Br J Gen Pract 2011;61:e404-10.

8. Duckworth AL, Peterson C, Matthews MD, Kelly DR. Grit: perseverance and passion for long-term goals. J Pers Soc Psychol 2007;92:1087-101.

9. Duckworth AL, Quinn PD. Development and validation of the short grit scale (grit-s). J Pers Assess 2009;91:166-74.

10. Reed AJ, Schmitz D, Baker E, Nukui A, Epperly T. Association of "grit" and satisfaction in rural and nonrural doctors. J Am Board Fam Med 2012;25: 832-9.

11. Kjeldmand D, Holmstrom I. Balint groups as a means to increase job satisfaction and prevent burnout among general practitioners. Ann Fam Med 2008;6:138-45.

12. Heiligers PJ, de Jong JD, Groenewegen PP, Hingstman L, Volker B, Spreeuwenberg P. Is networking different with doctors working part-time? Differences in social networks of part-time and full-time doctors. BMC Health Serv Res 2008;8:204.

13. Longenecker R, Zink T, Florence J. Teaching and learning resilience: building adaptive capacity for rural practice. A report and subsequent analysis of a workshop conducted at the Rural Medical Educators Conference, Savannah, Georgia, May 18, 2010. J Rural Health 2012;28:122-7.
14. Sinclair-Lian N, Rhyne RL, Alexander SH, Williams RL. Practice-based research network membership is associated with retention of clinicians in underserved communities: a research involving outpatient settings network (RIOS Net) study. J Am Board Fam Med 2008;21:353-5.

15. Michener L, Cook J, Ahmed SM, Yonas MA, Coyne-Beasley T, Aguilar-Gaxiola S. Aligning the goals of community-engaged research: why and how academic health centers can successfully engage with communities to improve health. Acad Med 2012;87: 285-91.

16. Newton WP, DuBard CA. Shaping the future of academic health centers: the potential contributions of departments of family medicine. Ann Fam Med 2006;4(suppl 1):S2-11.

17. Reece EA, Chrencik RA, Miller ED. Fully aligned academic health centers: a model for 21 st-century job creation and sustainable economic growth. Acad Med 2012;87:982-7.

18. Steiner BD, Calleson DC, Curtis P, Goldstein AO, Denham A. Recognizing the value of community involvement by AHC faculty: a case study. Acad Med 2005;80:322-6.

19. Woollard R. AHSCs: the complex simplicity of service. Healthc Pap 2002;2:90-5; discussion 111-4.

20. Poses RM, Smith WR, Maulitz R. Resilience training and physician well-being. J Gen Intern Med 2011;26:1243; author reply 1244-5.

21. Association of American Medical Colleges. Summary of PPACA Provisions Related to HRSA's Health Professions Programs and Other PHSA Workforce Programs. Available at: www.aamc.org/ download/131010/data/hrsa.pdf.pdf. Accessed September 1, 2012.

22. Phillips RL Jr, Turner BJ. The next phase of Title VII funding for training primary care physicians for America's health care needs. Ann Fam Med 2012;10: 163-8. 